\title{
Clinical Impacts of ST-Segment Non-Resolution after Thrombolysis for Myocardial Infarction
}

\author{
SYED AMINUL ISLAM ${ }^{1}$, MD. FARUQUE ${ }^{1}$, FAZLUR RAHMAN ${ }^{2}$, HARISUL HOQUE ${ }^{2}$, NILUFAR FATEMA ${ }^{2}$ \\ ${ }^{1}$ Department of Cardiology, National Institute Cardiovascular Disease, Dhaka, ${ }^{2}$ Department of Cardiology, Bangabandhu Sheikh \\ Mujib Medical University, Dhaka \\ Address of Correspondence: Dr. Syed Aminul Islam, Assistant Professor of Cardiology, NICVD, Dhaka. \\ E-mail:nilufar.fatema@gmail.com
}

\begin{abstract}
:
Streptokinase therapy for acute myocardial infarction reduces early mortality and improves outcomes. Failure of reperfusion after streptokinase therapy for acute myocardial infarction is common and indicates a poor prognosis. We investigated the clinical consequences of non-resolution of the ST segment after thrombolytic therapy for acute ST-elevation myocardial infarction, in 80 consecutive patients admitted to a coronary care unit. Failed thrombolysis was defined as $<50 \%$ ST-segment resolution at 90 minutes after the start of thrombolytic treatment. Outcomes were measured in terms of in hospital adverse events and mortality at 6 weeks. Thrombolysis was successful, in terms of ST-segment resolution, in 59 patients (73.75\%). After adjustment for other factors, $S T$ resolution was the only independent predictor of an uncomplicated recovery in hospital. ST-segment resolution is a useful marker of successful thrombolysis and relates to clinical outcome. Average hospital stay was 2 days greater in non resolved ST-segment group than in ST-segment resolved group. At 6 weeks overall early mortality was much lower in the ST segment resolution group (1.7\% versus $57.1 \%$ with P value of $<0.001$ ). So, non resolution of ST-segment in electrocardiogram following thrombolytic therapy in acute STEMI has paramount importance. If assessed routinely it might assist, along with other clinical markers, in the identification of high risk patients.
\end{abstract}

University Heart Journal 2019; 15(1): 3-7

\section{Methodology :}

This was a prospective analytical study conducted in the department of cardiology, Sir Salimullah Medical College and Mitford Hospital, Dhaka and NICVD, Dhaka from March 2004 to February 2005. Patients included in this study having acute ST elevation myocardial infarction admitted in hospital within 12 hours of onset of symptoms. Patients excluded from study were those, who had conventional contraindications for thrombolytic. Sample size of this study was considered eighty. The sample size was selected purposively. A questionnaire was prepared on the basis of history, clinical examination, risk factors and socio-demographic characteristics. A check list was prepared on the basis of serial ECG recordings for up to 180 minutes and follow up of every patient for up to 6 weeks. Among these, ST-segment resolution at 90 minutes in ECG was the principal determinant of this study. Relevant data's were collected by taking detailed history and doing physical examination of selected patients. Age, gender, risk factors were determined. Pulse, blood pressure, heart and lungs were examined and killip class determined in every patient. Standard 12 lead ECG was recorded in all patients. The ECG findings emphasized on rate, rhythm, QRS axis, PR interval, QRS duration, voltage criteria, $\mathrm{R}$ wave, $\mathrm{Q}$ wave, changes in ST segment and in T waves. Patients having acute ST-segment elevation of $\geq 1 \mathrm{~mm}$ in at least $2 \mathrm{limb}$ leads or ST-segment elevation of $\geq 2 \mathrm{~mm}$ in $\geq 2$ contiguous precordial leads were included in this study. After administration of streptokinase, ECG was done at 30 minutes, 60 minutes, 90 minutes and 180 minutes to see whether ST segment resolution occurs or not. ST segment resolution was set as $50 \%$ or more fall of elevated ST segment from baseline value within 90 minutes of starting streptokinase. Study cases were divided into two groups on the basis of ST segment resolution. ST segment resolved group and ST segment non resolved group. Streptokinase was administered to all included patients. All studied cases were followed up for up to six weeks from the time of enrollment into study. Every patient 
was intensively examined in hospital from admission to discharge. All patients were closely observed to detect whether any serious complications like arrhythmia, heart failure and reinfarction developed or not. After discharge patients were visited on 15th, 30th and 45th day and patients who did not visit hospital, information's were collected over telephone. Mortality status was done in relation to ST segment resolution. Data obtained from study was analyzed and significance of difference was estimated by using the statistical methods. Data's were expressed in frequency, percentage, mean and standard deviation as applicable. Comparison between groups was done by student ' $t$ ' test, chi-square test and multivariate analysis as applicable. Variables with a p-value of $<0.05$ was counted as significant and p-value of $>0.05$ was counted as insignificant. All statistics were calculated with SPSS software version 11.0

\section{Results:}

\section{Table I}

Demographic Profile of Study Population

\begin{tabular}{ll}
\hline Total Number of Patients & $: 80$ \\
Male & $: 74(92.5)$ \\
Female & $: 6(7.5)$ \\
Male Female ratio & $: 12.33: 1$ \\
Age range & $: 25-70$ Years. \\
Mean Age & $: 51.21 \pm$ SD 10.89 \\
Urban Population & $: 52$ \\
Rural Population & $: 28$ \\
\hline
\end{tabular}

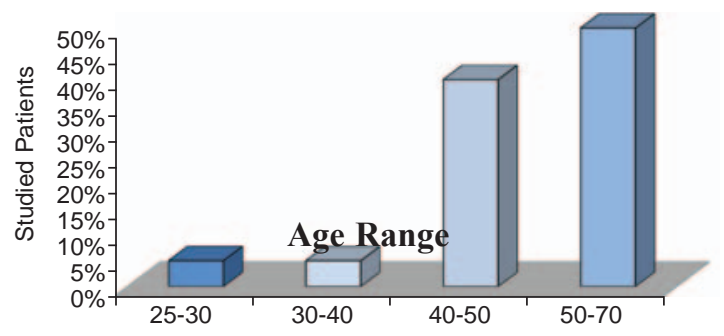

Fig.-1: Age distribution of studies cases

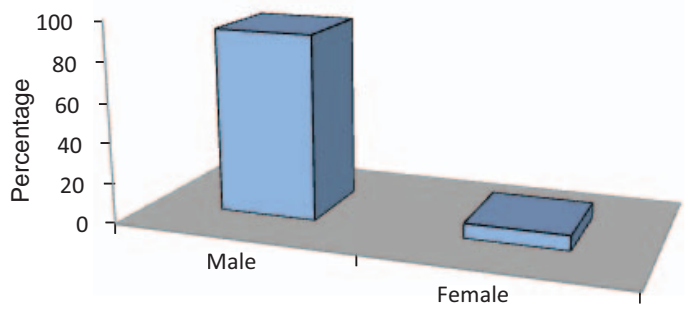

Fig.-2: Sex distribution of studied patient

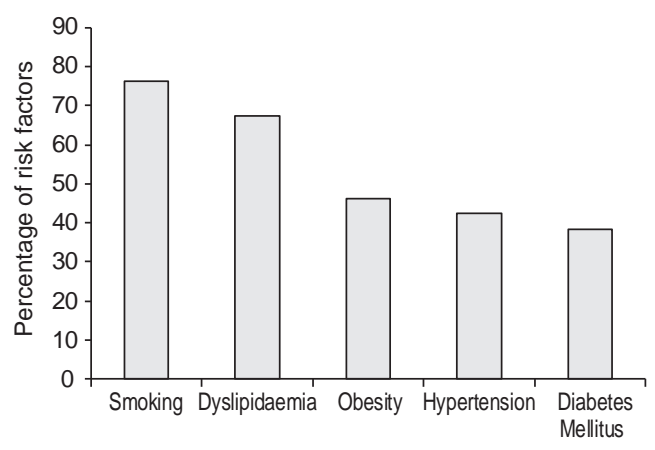

Risk factors

Fig.-3: Distribution of risk factors

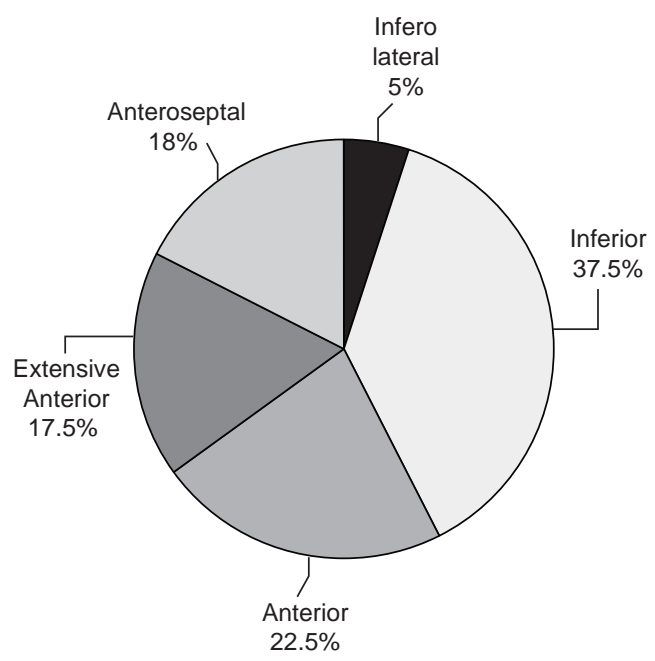

Fig.-4: Site of Acute Myocardial Infarction

Table-II

50\% ST segment resolution at 90 minutes after administration of streptokinase. 
Table-III

Clinical characteristics according to ST segment resolution at 90 minutes

\begin{tabular}{lccc}
\hline Variables (\%) & $\begin{array}{c}\text { ST-segment } \\
\text { resolved }\end{array}$ & $\begin{array}{c}\text { ST-segment not } \\
\text { resolved }\end{array}$ & P-Value \\
\hline Age (Years) ${ }^{\mathrm{n}}$ & $50(40-60)$ & $50(47-65)$ & .162 \\
Male Gender & 94.9 & 85.7 & .169 \\
Smoking & 76.3 & 76.2 & .994 \\
Hypertension & 37.3 & 57.1 & .114 \\
Diabetes Mellitus & 33.89 & 52.38 & .135 \\
Dyslipidaemia & 66.1 & 71.4 & .654 \\
Obesity & 49.2 & 66.7 & .167 \\
Positive Family History & 11.9 & 14.9 & .773 \\
Heart Rate (bpm) & n & $(68-88)$ & .152 \\
Systolic Blood Pressure Anterior wall MI & $120(100-130) 67.8$ & $130(105-140) 47.6$ & .214 .326 \\
Killipclass $>1$ & 18.64 & 23.80 & .611 \\
Time to Therapy (minute) ${ }^{\mathrm{n}}$ & $300(225-420)$ & $360(240-502)$ & .606 \\
\hline “n”.
\end{tabular}

" $n "=\operatorname{median}\left(25^{\text {th }}-75^{\text {th }}\right.$ percentile $)$

Table IV

Mortality status in relation to ST segment resolution

\begin{tabular}{lccccc}
\hline ST-segment & \multicolumn{2}{c}{ Survived } & & \multicolumn{2}{c}{ Died } \\
\cline { 2 - 3 } \cline { 4 - 6 } & No. & $\%$ & & No. & 1.7 \\
\hline ST-segment resolved & 58 & $* * * 98.3$ & & 1 & $* * * 57.1$ \\
ST-segment not resolved & 9 & 42.9 & & 12 & $* *$. \\
\hline
\end{tabular}

$* * * \mathrm{P}<0.001$ in $\mathrm{Chi}-$ Square test.

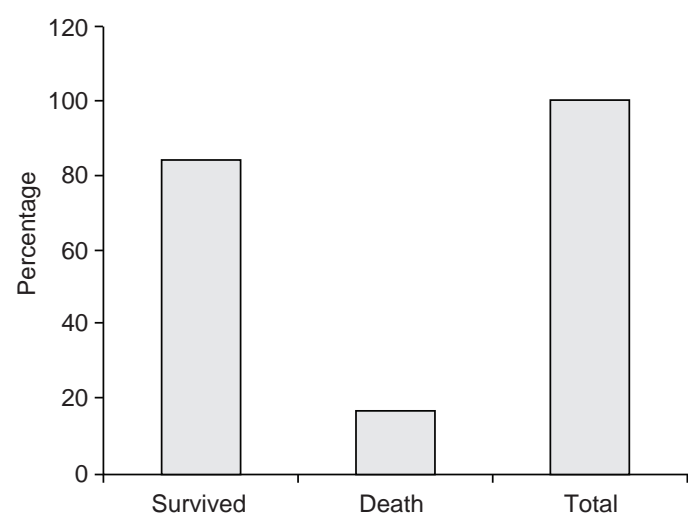

Fig.-5: Overall mortality status

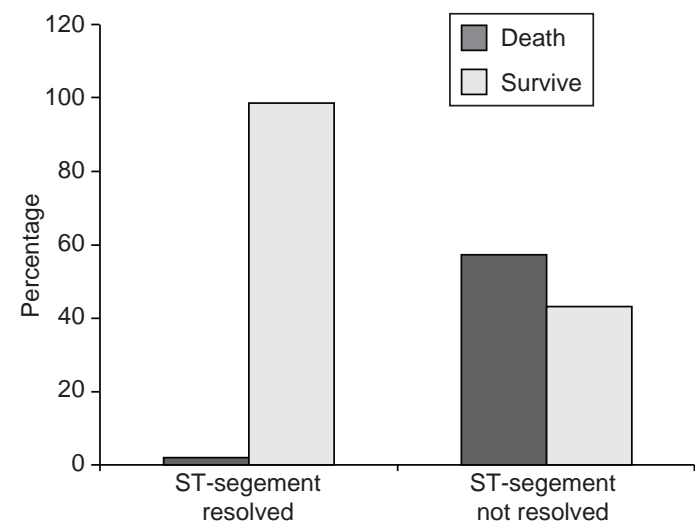

Fig.-6: Mortality status in relation to ST-segment resolution

Table-V

Death stratification in relation to streptokinase therapy

\begin{tabular}{lc}
\hline Starting of Streptokinase & Percentage of Deaths \\
\hline Within 6 hours of onset of symptoms & 46 \\
6 to 12 hours from onset of symptoms & 54 NS \\
\hline
\end{tabular}




\section{Discussion:}

Studied populations were in the age range of 25-70 years. Most of the patients were between 50 to 70 yrs. Male female ratio of patients were 12.33:1. 76\% patients were smoker. Smoking was more commonly found risk factor followed by dyslipidemia, obesity, hypertension and diabetes among studied populations. Inferior M.I. was commonly found in enrolled patient, which was $37.5 \%$ followed by anterior M.I. found in $22.5 \%$ patients. Clinical characteristics were evaluated in study population according to ST-Segment resolution at 90 minutes. Median age was 50 in both ST segment resolved group and ST-segment non resolved group. 94\% patients were male in ST-segment resolved group. Smoking was the most common risk factor in both group. Hypertension, diabetes mellitus, dyslipidemia and obesity were more prevalent in patients with non resolved ST-segment group. Anterior wall myocardial infarction was more common in patients with ST-segment resolved group. Time interval between onset of symptoms of acute myocardial infarction and starting of streptokinase was 360 minutes in patients with non resolved ST segment group and it was 300 minutes in patients with ST segment resolved group. Killip class $>1$ was present in $18 \%$ patient with ST-segment resolved group and in 24\% patient with non resolved ST-segment group. P value is not significant in any variables. After administration of streptokinase ST segment was resolved in 59 patients, that is STsegment resolution of $\geq 50 \%$ occurred at 90 minutes in these patients and ST segment was not resolved in 21 patients. Among ST segment resolved group early mortality was only 1.7 percent and early mortality was 57.1 percent in non resolved ST segment group, which is highly significant with a $P$ value of $<0.001$. In ASSENT trial early mortality was $1.4 \% .^{13}$ The mean symptom duration was $168 \mathrm{~min}$ in our study compared to $357 \mathrm{~min}$ in the single-centre study. ${ }^{14}$ ST-segment resolution at 90min was in the present study independently associated with higher early mortality as in previous studies. ${ }^{15}$ In this study death rate was higher in patients received streptokinase after 6 hours of onset of symptoms than in patients who received within 6 hours of symptoms (54\% versus $46 \%$ ). Patients without very early signs of reperfusion but with a short symptom duration of less than 2 hours and more frequently achieved ST-segment resolution at least within $180 \mathrm{~min}$, which has been previously associated with a smaller infarct size and better outcome. ${ }^{16}$ Hence this might indicate a greater extent of myocardial salvage as a result of shorter time to therapy. However, only one large study has been able to show independent prognostic value of both symptom duration and late ST-segment resolution after adjusting for other risk factors. ${ }^{17} \mathrm{ST}$ segment resolution was less likely to be achieved in the troponin I positive compared to the troponin I negative patients. This relation has previously been shown only in a small study by Frostfeldt et al, where the percentage ST segment resolution was less in the group with troponin I elevation. ${ }^{18}$ Several studies have shown that ST-segment resolution is a more sensitive marker of tissue level reperfusion than of epicardial flow. However, the fact that no ST resolution at $90 \mathrm{~min}$ was independently related to higher early mortality. Time to ST segment resolution also suggest complementary pathophysiological mechanisms concerning their relation to early mortality. ST segment resolution measures the effect of treatment on tissue level reperfusion and subsequent myocardial salvage. As in previous trials, the variables e.g. age, heart rate and systolic BP constituting the risk index proposed by Morrow et al, were strong independent predictors of early mortality. ${ }^{19}$ Length of study was calculated only in patients who survived to hospital discharge. Overall median length of hospital stay was two days greater in non resolved ST segment group than in successfully thrombolysed group ( 9 days versus 7 days). Patients who did not experience an adverse event in the first 72 hours after admission remained event free subsequently while in hospital. From the GUSTO-1 population, it has been shown that electrocardiographic signs of reocclusion, i.e. ST-elevation, 6-24 hours after thrombolysis, predicts worse prognosis. ${ }^{20}$ Furthermore, it is previously seen in ASSENT trial that even very small variations of the ST-segment during first 4 hours of observation have a negative effect on 30 day and 1 year outcome. A rational way to use this information in the clinical setting would be to continuously risk-stratify the patient. Our data suggest that a first evaluation of treatment can be done. And support for clinical decision making may already be available at 90 minutes. If the patient reached $50 \%$ ST-resolution, myocardial flow is most probably restored and the patient belongs to low risk group. If not, it may time to prepare further invasive or pharmacological treatment. This study highlights the poor clinical outcome of patients with ST-segment non resolution after thrombolytic treatment, indicated by simple evaluation of the post thrombolysis electrocardiogram.

\section{Conclusion:}

Stratifying the risk in patients with acute myocardial infarction is an essential part of the management strategy 
during all phases of care of these patients. It permits not only the more precise calibration of treatment and diagnostic approaches with the level of risk but also increasingly facilitate the appropriate utilization of hospital resources. Continuous ST-monitoring of patients with acute myocardial infarction yields important prognostic information after 90 min of observation and should be used for very early risk stratification and supports a future basis for individualized treatment of these patients.

ST segment resolution at 90 minutes are strong predictors of early mortality and gives additive early information about prognosis and further improves risk stratification in acute STEMI. An approach for risk stratification and treatment strategy can be suggested from our findings:

No ST segment resolution indicative of failed epicardial and/or tissue level reperfusion. These patients have a high mortality risk.

An early ST- resolution as indicated by ST-segment resolution at 90 minutes are at low risk. Thus there treatment seems sufficient.

\section{References:}

1. Antman EM, Braunwald E . Acute myocardial infarction. In: Braunwald E (ed). Heart disease: A Textbook of Cardiovascular Medicine, 5th ed. WB Saunders Company, Philadelphia. 1997;p.1174-78.

2. Boon NA, Fox KAA, Bromfield Pl. Diseases of the cardiovascular system, In; Haslett C, Chilvers ER, Hunter JAA, Boon NA (eds). Davidson's principles and Practice of Medicine, 19th ed. Churchill Livingstone, Edinburgh. 1999;p.191-302.

3. Malik A, Islam MN, Zafar A, Khan AK, Ramizuddin M. Clinical patterns of ischemic heart diseases and its association with some known risk factors. Bangladesh Heart J. 1987;2:1-9.

4. Apple FS. Cardiac troponin: Redefining the detection of myocardial infarction. American Clinical Laboratory. 2002;1:32-33.

5. Lee K1, Woodlief LH, Topol EJ. Predictors of 30-day mortality in the era of reperfusion for acute myocardial infarction. Results from an international trial of 41,021 patients. GUSTO-1 investigators. Circulation. 1995;91:1659-68.

6. LincoffAM, Topol EJ. Illusion of reperfusion. Does anyone achieve optimal reperfusion during acute myocardial infarction? Circulation. 1993;88(3):1361-74

7. Itoh, Tomooka T, Sakai N, et al. Lack of myocardial perfusion immediately after successful thrombolysis. A predictor of poor recovery of left ventricular function in anterior myocardial infarction. Circulation. 1992;85(5):1699-05
8. BarbashGI, Roth A, Hod H, et al. Rapid resolution of ST elevation and prediction of clinical outcome in patients undergoing thrombolysis with alteplase: results of the Israeli study of early intervention in Myocardial infarction. Br Heart J.1990;64(4):241-47

9. KrucoffMW, Green CE, Satler LF, et al. Non invasive detection of coronary artery patency using continuous ST-segment monitoring. Am J Cardiol.1986;57(11):916-22

10. Langer A, Krucoff MW, Klootwijk P, et al. Prognostic significance of ST segment shift early after resolution of ST elevation in patients with myocardial infarction treated with thrombolytic therapy: the GUSTO-I ST Segment Monitoring Substudy. J Am Coll Cardiol. 1998;31(4):783-89

11. Schroeder R, Wegscheider K, Schroeder K. Extent of early ST segment elevation resolution: a strong predictor of outcome in patients with acute myocardial infarction and a sensitive measure to compare thrombolytic regimens. J Am Coll Cardiol. 1995;26: $1657-64$.

12. Shah A, Wagner GS, Grange CB. Prognostic implications of TIMI flow grade in the infarct related artery compared with continuous 12-lead ST-segment resolution analysis. Reexamining the "gold standard" for myocardial reperfusion assessment. J Am Coll Cardiol. 2000;35(3):666-72.

13. Johanson P, Jernberg T, Gunnarsson G, et al. Prognostic value of ST-segment resolution-when and what to measure. Eur $\mathrm{H}$ Journ.2003;24(4):337-45

14. Bjorklund E, Lindahi B, Johanson P, Jernberg T, Venge P, Wallentin L, Dellborg M1. Admission troponin T and measurement of ST segment resolution at 60 minutes improve early risk stratification in ST elevation myocardial infarction. Euro H Journal. 2004;25: 111-20.

15. Giannitsis E, Lehrke S, Wiegand UK . Risk stratification in patients with inferior acute myocardial infarction treated by percutaneous coronary interventions: the role of admission troponin $\mathrm{T}$. Circulation. 2000;102:1611-16.

16. Maron DJ, Ridker PM, Pearson TA. Risk factors and prevention of coronary heart disease. In: Alexander RW, Schlant RC,Fuster V (eds). Hurst's The Heart, volume 1,9 $9^{\text {th }}$ ed. McGraw-Hill Book Inc.,New York. 1998:p,1175-85.

17. Fu Y, Gooodman S, Chang WC. Time to treatment influences the impact of ST-segment resolution on one year prognosis insights from the assessment of the safety and efficacy of a new thrombolytic trial. Circulation. 2001;104:2653-59.

18. Frostfeldt G, Gustafsson G, Lindahi B . Possible reasons for the prognostic value of troponin $\mathrm{T}$ on admission in patients with ST elevation myocardial infarction. Coron Artery Dis. 2001;12:227-37.

19. Morrow DA, Antman EM, Giuliani RP . A simple risk index for rapid initial triage of patients with ST elevation myocardial infarction: an In TIME II substudy. Lancet. 2001;358:1571-75.

20. Johanson P, Svensson AM, Dellborg M. Clinical implications of early ST-segment variability. A report from the ASSENT 2 STmonitoring sub-study. Coron Artery Dis. 2001;12(4):277-83. 